\title{
Examining the Prediction Role of Spiritual Intelligence and Gender in Moral Reasoning
}

\author{
Mohammed Alkiyumi ${ }^{1} \&$ Saja Alferisi ${ }^{2}$ \\ ${ }^{1}$ Faculty of Education and Arts, Sohar University, Sohar, Sultanate of Oman \\ ${ }^{2}$ Ministry of Education, Sultanate of Oman \\ Correspondence: Mohammed Alkiyumi, Faculty of Education and Arts, Sohar University, Sohar, Sultanate of \\ Oman. Tel: 968-9936-2383. E-mail: mkiyumi@su.edu.om
}

\author{
Received: March 16, 2019 \\ Accepted: April 21, 2019 \\ Online Published: April 30, 2019 \\ doi:10.5539/ass.v15n5p59 \\ URL: https://doi.org/10.5539/ass.v15n5p59
}

\begin{abstract}
The prediction role of spiritual intelligence in moral reasoning is studied in a sample of 249 students (124 males, 125 females), from $11^{\text {th }}$ grade of government schools in Wilayat Alsuwaiq, in North Albatinah region in the Sultanate of Oman. Gibbs et al., (1984) inventory is used to measure moral reasoning, and King (2008) inventory is used to measure spiritual intelligence. The findings indicate that spiritual intelligence and gender predict moral reasoning, while spiritual intelligence contributes significantly to the total score of moral reasoning as opposed to gender which does not. In addition, moral reasoning does not differ significantly by gender, whereas spiritual intelligence does. Future research is needed to investigate different factors that may have an effect on students' moral reasoning.
\end{abstract}

Keywords: spiritual intelligence, moral reasoning, religiosity, gender

\section{Problem Statement}

Moral reasoning is one of the personality components which consists of the deepest values, most of which reflect norms of a specific culture (Baumsteiiger, Chenneville, \& McGuire, 2013). Research on moral development derives its roots from the Piaget's work which tried to match the children deeds according to an upholding responsibility. Consequently, Kohelberg provided his theory on moral judgment and moral reasoning which to him delineates that moral reasoning has three levels: pre-conventional, conventional, and post-conventional. Kohelberg expanded the moral development concept, and asserted that the role playing and recognition of culture and others are very important factors on the pre-conventional stage, whereas, the experience on moral decision taking is influential on the last stages (Aleixo, 1992).

Moral reasoning development reflects cognitive development which the education given in the family or in the schools play vital role to shape. Through moral reasoning development, people transfer from egocentric to community centric which is more rational. When people start to relate with others, their morality focuses on the exchange of personal expectations, and moral principles (Allahyani, 2011; Alghamdi, 2015).

Moral reasoning is affected by many factors, the family is a major factor which shapes the morality of people, and moral development can be predicted via parents' education (Ahmed, 2013).

Schools play a main role in morality development, because they offer such activities that enable the students to experience different good values such as, honesty, cooperation, helping others, and upholding responsibilities (Mayhew \& King, 2008). The advanced technologies especially social media affect peoples' habits and attitudes. The media has an essential role on cultural characteristics within different areas, and some of these characteristics are not well received by some areas (Allahyani, 2011).

Religiosity is an essential component of life in the conservative countries, because it influences many aspects extending to regulation and law systems, additionally it affects the peoples' intellectuality and mindset. Indeed, the religiosity education that is imposed upon students rely heavily on the rituals, and worship. Very little attention is being given to raising the thinking, criticism, synthesis, judging, and or even to deep discussion and arguments (Zahid, 2009).

Clearly, the explanation of Piaget and kohelberg regarding moral thinking is based on peoples' evaluation of 
their behavior due to observed consequences and consideration of intention in justifying their judgement. They argued that a child's morality develops through the interactions that are built into the social community, which enables them to deal with various experiences (Redzic, 2015).

Moral reasoning affected by religious education as Kohelberg indicated suggests that there is a balance between moral reasoning and religious thinking, and there are very identical elements between them, but the impact of religious education on developing morality is still limited and needs an in-depth investigation. Rajia and Ibrahim (2005) insisted that people adopt moral judgments on any issues based on a religious background which shield them from any conflict and get the feeling of tranquility and safety. On the other hand, Kohelberg emphasized that there is no need for religiosity on developing moral reasoning because the religious principals are not unified (Almosawi, n. d.).

Kohelberg provided comprehensive principals in his effort to theorize that religious constraints and beliefs have a limited effect on the development of morality. This view was criticized by some scholars who asserted that spiritual thinking is innate to humans, therefore it affects somehow the moral judgements of many people especially the religious ones (Rajia \& Ibrahim, 2015).

In his theory "Multiple Intelligence" Gardner (1999) asserted that most contributions provided for developing students' learning are directing their potential and interests. He stated that every person has various capabilities which he called "Human Intelligences" (seven intelligences). Emmons (2002) added spiritual intelligence as a unique intelligence when he emphasized that spirituality consists of abilities and aptitudes which are foundational, and asserted that spiritual intelligence enables the people to solve problems. Each intelligence has specific traits and characteristics related to problem solving. Lawrence study as cited in (Aldaftar, 2011) showed that people have different abilities of spiritual intelligence, and the mind can shift from metacognition to spiritual cognition, thus his process makes spiritual intelligence a measurable entity.

Bozan (2007) articulated that spiritual intelligence helps to connect with and understand nature, acquiring positive traits, and protecting emotional and moral identity. Spiritual intelligence consists of personal intelligence which is concerned with self-understanding and self-esteem, and social intelligence that is focused on others' understanding and others' esteem. Khoshtinat's study (2012) found that spiritual intelligence abilities and religiosity are acquired in the childhood period. Ali (2015) found that spirituality plays vital role on developing the human mind in self and others understanding.

Communities that are facing various moral problems such as terrorism, intellectual violence, misbehaviors, and cheating (Moshraf, 2009). These types of problems raise extensive arguments about the communities' moral homogeneity. In some regions like Oman, religiosity is a very influential factor that determines peoples' values and behaviors. Recently, some dramatic changes appeared which may diminish the role of spirituality instead. Indeed, advanced technology, people's interests, and openness to other cultures are the factors that form the peoples' morality.

Therefore, this study tries to examine the prediction role of spiritual intelligence in moral reasoning among $11^{\text {th }}$ grade students in Oman. The children in Oman get educated spiritually in different places such as, families and mosques, in addition, schools provide Islamic Education subjects throughout the different grades. These varied types of education aim to raise spirituality among the students, and enhance their morality. Up to date, there is no study that investigates this relationship in Oman. The only similar study was conducted by Alsubhi (2013) which found that Spiritual intelligence predicted achievement, establishing that there was no significant difference between males and females in spiritual intelligence.

When looking back to the previous studies, inconsistent findings emerge. Studies by (Abu Aldeyar, 2015; Baumsteiger, Chenneville, \& McGuire, 2013; Glover, 1997; Zaman, 2010) found a positive relationship between religiosity and morality. The studies of (Abu Qaood, 2008; Smartt, 2014) found that there is a weak relationship between religiosity level and moral reasoning. The studies' findings of morality with regard to gender are inconsistent. Some researchers (Alzobaidia, 2016; Alsaied, 2014; Byers \& Powers, 1997) showed that men have higher morality than women, whereas others have found the opposite (Allmon, Page, \& Roberm, 2000; Wilson, 2003).

\section{Study Design}

Sample: The study's population are all the $11^{\text {th }}$ grade students in wilayat Alsuwaiq which consists of 2223 in 10 government schools, the probability sample is 249 selected by the cluster technique. The 10 classes of male and female students form the clusters. 


\subsection{Instruments}

\subsubsection{Moral Reasoning Inventory}

This instrument is provided by Gibbs et al. (1984) to assess moral reasoning among the students which is based on Kohelber's theory. It consists of two stories which end up with issues that need moral judgements. This inventory has seven questions following the first story, and six questions after the second story; these 13 questions are based the following moral criteria: contract and truth, affiliation, life, law and property, and legal justice. The participants are asked to make moral judgements such as to steal or not, necessary or not necessary. Every question has two parts. Firstly, the respondent has to determine the justifications of his judgement from six alternatives. The five justifications represent the fifth stages of moral reasoning, and the sixth is ambiguous to discover lies or careless responses. In the second part, the respondent has to determine the most important justifications. The psychometric properties were measured. The validity of this inventory was measured by two types: content validity and sampling validity, and the specialists' review was considered.

In addition, concurrent validity was measured. Gibbs et al. (1984) found correlation coefficient $r=.68$, and 0.89 with Kohelberg inventory and Rest inventory respectively. Alghamdi (2000) found correlation coefficient $r=$ 0.73 with Gibbes et al inventory and Socio-moral Reflection measure - Short form. Accordingly, this study measured concurrent validity among 80 students from the population, and found coefficient $r=0.83$ with Alghamedi inventory. The internal consistency reliability was measured among sample of 80 students. The Cronbach Alpha reliability coefficient was 0.72 .

\subsubsection{Spiritual Intelligence Inventory}

This tool is provided by King (2008) (SISRI-24). It has 24 items varied into four domains: critical-existential thinking, personal meaning production, transcendental awareness, and conscious status expansion. Critical existential thinking is the first component of spiritual intelligence. It is defined as the capacity to critically think about the nature of existence, reality, the universe, space, time, death, and other existential or metaphysical issues. The second one refers to creating personal meaning and purpose in all physical and mental experiences, such as the capacity to create a purpose in life. Transcendental awareness as the third component of spiritual intelligence is defined as the capacity to recognize transcendent dimensions of the self, of others, and of the physical world throughout normal states of consciousness, with the capacity to identify their relationship to one's self and to the physical world (King, 2008). The last factor which is Conscious Status Expansion refers to a capacity to immerse through higher/spiritual states of consciousness like pure consciousness and cosmic consciousness at one's own discretion. A significant relationship between spiritual intelligence and mental health has been reported in previous studies (Emmons, 2000).

The psychometric properties of this inventory were measured. Content validity of item validity and sampling validity were all measured. Additionally, the specialist view is very important to determine the appropriateness of every item in this religious area. Their review and comments are considered.

The internal consistency reliability was measured among a sample of 80 students by Cronbach alpha. The reliability coefficient was 0.80 . Table 1 shows the reliability coefficient in this study for every domain as compared with the reliability coefficient of King.

Table 1. Reliability coefficients of spiritual intelligence inventory

\begin{tabular}{ccc}
\hline Domains & Reliability Coefficient in this study & Reliability Coefficient in King study \\
\hline Transcendental awareness & 0.86 & 0.87 \\
Critical existing & 0.78 & 0.78 \\
Personal meaning production & 0.82 & 0.78 \\
Conscious expansion & 0.78 & 0.91 \\
Total & 0.80 & 0.92 \\
\hline
\end{tabular}

\subsection{Data Analysis}

The data was entered in SPSS, the descriptive and inferential analysis was obtained. After considering missing data, central tendencies and dispersion measures were obtained as well as other measures of normal distribution. To answer the study's questions, multiple regression and One Way MANOVA were used after checking the assumptions use. 


\section{Findings}

Q1. How well do the predictors combination of gender and spiritual intelligence predict the moral reasoning?

The model summary in the Table 2 shows that the multiple correlation coefficient $\mathrm{R}$ using the predictors of Spiritual intelligence and gender simultaneously is $2, \mathrm{R}^{2}=.046$, and the adjusted $\mathrm{R}^{2}=.038$. It means that mostly $4 \%$ of variance on moral reasoning can be predicted by gender and spiritual intelligence.

Table 2. Model Summary

\begin{tabular}{ccccc}
\hline Model & $\mathrm{R}$ & $\mathrm{R}$ Square & Adjusted R Square & Std. Error of the Estimate \\
\hline 1 & $.213^{\mathrm{a}}$ & .046 & .038 & .28732 \\
\hline
\end{tabular}

ANOVA's showed in the Table 3 that $F=5.86, \mathrm{~F}=(2,246), \mathrm{p}=.003$ which means that the combination of gender and spiritual intelligence predict the moral reasoning significantly.

Table 3. ANOVA

\begin{tabular}{ccccccc}
\hline & Model & Sum of Squares & $\mathrm{df}$ & Mean Square & $\mathrm{F}$ & Sig. \\
\hline \multirow{4}{*}{1} & Regression & .968 & 2 & .484 & 5.865 & $.003^{\mathrm{b}}$ \\
& Residual & 20.308 & 246 & .083 & & \\
& Total & 21.276 & 248 & & & \\
\hline
\end{tabular}

This result is consistent with studies of Kumari and Khadi (2018), and Zaman (2010). On the other hand, this result is contradictory with studies by (Abu Qaood, 2008; Smartt, 2014). Spiritual intelligence and gender accounted for a very little variability in moral reasoning; however, suggesting that they do not directly influence moral reasoning. In addition, female participants reported higher spirituality, but there were no gender differences on a spirituality measure.

Q2. Are there differences between male and female in the linear combination of spiritual intelligence and moral reasoning?

Descriptive statistics measures: mean and standard deviation for moral reasoning were obtained, $M=3.09$, $\mathrm{SD}=.32$ for male, and $\mathrm{M}=3.15, \mathrm{SD}=.26$ for female. On the other hand, the descriptive results of spiritual intelligence indicated that $\mathrm{M}=3.49, \mathrm{SD}=.67$ for male, and $\mathrm{M}=3.78, \mathrm{SD}=.57$ for female.

Two way MANOVA analysis was conducted to assess if there are any differences between gender on a linear combination of moral reasoning and spiritual intelligence. Wilks' Lambda $\Lambda=.945, F(2.24)=7.20$, multivariate $\eta^{2}=.55$.

Table 4. Parameter Estimates for Gender

\begin{tabular}{ccccccc}
\hline Effect & & Value & $\mathrm{F}$ & Hypothesis df & Error df & Partial Eta Squared \\
\hline Intercept & Wilks' Lambda & .008 & $16059.981^{\mathrm{b}}$ & 2.000 & 246.000 & .992 \\
Gender & Wilks' Lambda & .945 & $7.202^{\mathrm{b}}$ & 2.000 & 246.000 & .055 \\
\hline
\end{tabular}

Table 5 Shows that linear combination of moral reasoning was not differed regarding to the male and female, $p=.119$. In contrast, linear combination of spiritual intelligence is differed with regard to male and female, $\mathrm{p}=.000$.

Table 5. Tests of Between Subjects Effects

\begin{tabular}{cccccccc}
\hline \multirow{2}{*}{ Source } & $\begin{array}{c}\text { Dependent } \\
\text { Variable }\end{array}$ & $\begin{array}{c}\text { Type III Sum of } \\
\text { Squares }\end{array}$ & df & $\begin{array}{c}\text { Mean } \\
\text { Square }\end{array}$ & F & Sig. & $\begin{array}{c}\text { Partial Eta } \\
\text { Squared }\end{array}$ \\
\hline \multirow{2}{*}{ Intercept } & Total M & 2435.773 & 1 & 2435.773 & 28558.661 & .000 & .991 \\
& Total S & 3296.618 & 1 & 3296.618 & 8415.398 & .000 & .971 \\
\multirow{3}{*}{ Gender } & Total M & .209 & 1 & .209 & 2.453 & .119 & .010 \\
& Total S & 5.362 & 1 & 5.362 & 13.687 & .000 & .053
\end{tabular}


The result is consistent Abdein's study (2011) which showed that there are no significant differences in moral reasoning based on gender differences, but it contradicts studies such as those of Alsobhi (2013); Sobaih, Hasan, And Khazim (2017). In the same vein, it contradicts studies of Baumsteiger and Chenneville (2012), and Sarayana and Sangeetha (2017) which revealed that spiritual intelligence does not differ according to gender.

\section{Discussion}

This result indicates that moral reasoning is based on many factors such as the students' background, the education system and community regulations. In addition, the students at this age have to follow the disciplines of the families and obey their parents' orders, and most of the Omani families share the same attitudes and perceptions towards morality, so both genders should consider the impact of community morality on their behaviors. Therefore, gender does not contribute significantly to the total score of the moral reasoning, and moral reasoning does not seem to vary between both genders.

This result does not support the principles of Kohelberg theory which asserted that the morality of men exceeds women's morality. The main reason behind that is the type of culture differences. Oman is a conservative country in which basically the norms and culture specifics control people's morality as it places a premium on societal integration of all members instead of individualism. The students live with their families but such relatives as aunts, uncles, cousins also control and affect their personalities and behaviors. Furthermore, the other members of the society also play their roles in orienting the students' behaviors.

Spiritual intelligence contributes significantly to the total score of moral reasoning since linear combination of spiritual intelligence differs with regards to gender. Females are slightly better than males. This striking result may be due to the fact that females are more conservative in Omani culture, and they try to follow the culture norms, and the religious rituals. In addition, this result can be due the male-female personality differences. Females are more quiet and less critical, and they try to conform with the norms in put in place by the culture, parents and family. Obviously, the most powerful instructions that form life habits and principals are religious. Religiosity interposes with their thinking styles, which are reflected in their behaviors and living styles.

Spiritual intelligence contributed significantly to the variation of moral reasoning which may be stemming from the effective role that spirituality plays in people's lives (cognitions and behaviors) in this region. Additionally, the many religious instructions that educated students whether in their families, mosques, or in schools focus heavily on ethics and behaviors. These are instilled deep values, such as respecting others, helping older people, mercy, empathy, help oppressed people...etc. All these values help to construct and shape people's personalities and moral conduct. Therefore, when the main source of these values is a religious one, people accept and implement it in their lives.

\section{References}

Abdein, H. (2012). Spiritual intelligence and self-effectiveness and they impact on the pressured events among universities students. Education Journal of Cairo University, 150(2).

Abu Aldeyar, M. (2015). Effectiveness of consultant program on developing spiritual intelligence and reducing bully behavior among primary students. Journal of Social Science, 49(87).

Abu Qaood, A. (2008). Punishing experience of Palestinians prisoners and its relationship with moral reasoning. Unpublished master thesis. Islamic University in Gaza.

Ahmed, N. (2013). Luqman recommendations as a narrative approach in moral reasoning of kindergarten Childs. Journal of Childhood and Education, 15(5), 16-136.

Aldaftar, K. (2011). Childs'spiritual intelligence. Thought house: Amman.

Aleixo, P. A. (1992). Personality and Moral Reasoning in Young Offenders. University of Leicester.

Alghamdi, H. (2000). Development of moral reasoning among adult Saudi male. Journal of Education College, 16(16), 645-689.

Alghamdi, H. (2015). Moral reasoning inventory accumulative indicators review for validity and reliability in the Saudi community. Um Alquar University, Kingdom of Saudi.

Allahyani, A. (2011). Moral reasoning and its' relationship with social responsibility based on some academic variables among Um alquar students. Unpublished master thesis. Um alqura University, Saudi Kingdom.

Allmon, D. E., Page, D., \& Roberts, R. (2000). Determinants of perception of cheating: Ethical orientation, personality, and demographics. Journal of Business Ethics, 23, 411-422. https://doi.org/10.1023/A:1006087104087 
Al-musawi, A. (n. d.). When childe become philosopher: readings in cognitive and moral development (L. Kohelber Translated). Retrieved from http:// www.Al-musawi.com/docs/Child.pdf.2016/4/28

Alsaied, S. (2014). Moral reasoning and its relationship with big five personality factors among Sohaj university. Unpublished master thesis. Sohaj University. Egypt.

Alsobhi, H. (2013). Moral reasoning and its relationship with academic achievement among students of Sharia sciences centre in the sultanate of Oman. Unpublished master thesis. Nizwa University, Oman.

Alzobaidia, R. (2016). Spiritual intelligence and its relationship with cognitive beliefs among preparatory students. Unpublished master thesis. Wasit University, Iraq.

Baumsteiger, R., Chenneville, T., \& McGuire, J. F. (2013). The Roles of Religiosity and Spirituality in Moral Reasoning. Ethics \& Behavior, 23(4), 266-277. https://doi.org/10.1080/10508422.2013.782814

Bozan, T. (2005). Head first: 10 ways to tap into your natural genius. Jareer Publishing: Riyad.

Byers, B., \& Powers, W. G. (1997). Ethical orientations and criminal justice: The effects of academic major and gender. Journal of Criminal Justice Education, 8, 163-179. https://doi.org/10.1080/10511259700086281

Emmons, R. A. (2000). Is Spirituality Intelligence? Motivation, Cognition and the Psychology of Ultimate Concern. International Journal for the Psychology of Religion, 10(1), 3-26. https://doi.org/10.1207/S15327582IJPR1001_2

Gardner, H. (1999). Multiple Intelligence for the 21st Century. New York: Basic Books.

Gibbs, J. C., Arnold, K. D., Morgan, R. L., Schwartz, E. S., Gavaghan, M. P., \& Tappan, M. B. (1984, April). Construction and Validation of multiple-Choice measure of moral reasoning. Child Development, 55(2), 527-536. https://doi.org/10.1111/j.1467-8624.1984.tb00312.x

Glover, R. J. (1997). Relationships in moral reasoning and religion among members of conservative, moderate, and liberal religious groups. The Journal of Social Psychology, 137, 247-254. https://doi.org/10.1080/00224549709595435

Khoshtinat, V. (2012). Relationship between spiritual intelligence and religious(spiritual) coping among students of Payame Noor University. International Research Journal of Applied and Basic Science, 3(6), 1132-1139.

King, D. (2008). Rethinking claims of spiritual intelligence: A definition, model and measure. Trent University Peterborough, Canada. Retrieved from http://www.davidbking.net/researcher/thomashb.pdf

Kumari, P., \& Khadi, B. (2018). Inter-relation between moral judgment and spiritual intelligence of high school children. Journal of Farm Sci., 31(1), 108-111.

Mayhew, J. M., \& King, P. (2008). How Curricular Content and Pedagogical Strategies Affect Moral Reasoning Development in College Students. Journal of Moral Education, 37(1), 17-40. https://doi.org/10.1080/03057240701803668

Moshraf, M. (2009). Moral reasoning and its relationship with social responsibility and some variables among Islamic university students of Gaza. Unpublished master thesis. Islamic University, Gaza, Palestine.

Rajia, A., \& Ibrahim, I. (2005). Moral reasoning and social responsibility among Egyptian and Saudi students, and its relationship with personal and demographic variables. College of Education Journal, 61(15).

Redzic, S. (2015). Youth gender differences in moral reasoning on gender morality in the light of theories by Kholberg and Gilligan.

Saranya, R., \& Sangeetha, T. (2017, June). A study of spiritual intelligence in relation to achievement in science among secondary school students in Coimbatore educational district. RVS College of Education, India. International Journal of Research-Granthaalayah, 5(6), 2394-3629. https://doi.org/10.5281/zenodo.805861

Smartt, M. J. (2014). The Relationship of Spiritual Intelligence to Achievement of Secondary Students (PhD thesis). Retrieved from http://digitalcommons.liberty.edu/doctoral/820

Sobaih, S., Hasan, K., \& Khazim, S. (2017). Spiritual intelligence and its relationship with religiosity among Art's college students. Journal of Alqadesiya University, Iraq.

Wilson, M. S. (2003). Social dominance and ethical ideology: The end justifies the means? The Journal of Social Psychology, 143, 549-558. https://doi.org/10.1080/00224540309598462

Zahid, R. (2009). The relationship of psych-social development and morality with offending behavior: comparative between offenders and non-offender's female in Maka. Unpublished master thesis. Um Alqura 
University.

Zaman, S. (2010). Relationship Between Cognitive Levels, Moral Reasoning And Academic Achievement Of Secondary School Students (PhD thesis). University of the Punjab, Lahore.

\section{Copyrights}

Copyright for this article is retained by the author(s), with first publication rights granted to the journal.

This is an open-access article distributed under the terms and conditions of the Creative Commons Attribution license (http://creativecommons.org/licenses/by/4.0/). 